\title{
PENGARUH EXPERIENTIAL MARKETING TERHADAP LOYALITAS PELANGGAN (STUDI PADA ROXY MART KOTA PALU)
}

\author{
RASNI \\ H. CHALIL \\ RAHMAT MUBARAQ \\ Program Studi Manajemen Fakultas Ekonomi Universitas Tadulako \\ e-mail: rasniramli@gmail.com
}

\begin{abstract}
This study aims to) determine the influence of experiential marketing both simultaneously and partially to customer loyalty Roxy Mart Palu City. The independent variables used in this research are sense, feel, think, act, and relate. While the dependent variable is Customer Loyalty. The method used in this research is quantitative descriptive method. The type of research conducted is descriptive causal. The sample is 90 respondents with purposive sampling sampling technique. Data analysis method used in this research is multiple linear regression analysis method using SPSS 23. The result of this research shows that simultaneously experiential marketing consisting of sense, feel, think, act, and relate significantly influence customer loyalty Roxy Mart Palu City . Partially customer trust consisting of sense, feel, think, act, and relate have a significant effect to customer loyalty Roxy Mart Palu City.
\end{abstract}

Keywords: Experiential Marketing, customer Loyalty

\begin{abstract}
Abstrak
Penelitian ini bertujuan untuk mengetahui pengaruh experiential marketing baik secara serempak maupun parsial terhadap loyalitas pelanggan Roxy Mart Kota Palu. Variabel independen yang digunakan dalam penelitian ini adalah sense, feel, think, act, dan relate. Sedangkan variabel dependen adalah Loyalitas Pelanggan. Metode yang digunakan dalam penelitian ini adalah metode deskriptif kuantitatif. Jenis penelitian yang dilakukan adalah deskriptif kausal. Sampel berjumlah 90 responden dengan teknik pengambilan sampel purposive sampling. Metode analisis data yang digunakan dalam penelitian ini adalah metode analisis regresi linier berganda dengan menggunakan SPSS 23. Hasil penelitian ini menunjukkan bahwa secara simultan experiential marketing yang terdiri dari sense, feel, think, act, dan relate berpengaruh signifikan terhadap loyalitas pelanggan Roxy Mart Kota Palu. Secara parsial kepercayaan pelanggan yang terdiri dari sense, feel, think, act, dan relate berpengaruh signifikan terhadap loyalitas pelanggan Roxy Mart Kota Palu.
\end{abstract}

Kata kunci: Experiential Marketing, Loyalitas Pelanggan.

\section{PENDAhuluan}

Saat ini semakin banyak bisnis-bisnis sejenis yang didirikan, maka semakin ketat pula persaingan dalam dunia bisnis, terutama untuk bisnis-bisnis yang serupa. Pemimpin perusahaan tidak boleh lengah dan harus terus berusaha agar perusahaannya tetap unggul dan dapat terus bersaing dengan perusahaanperusahaan lainnya. jika menghadapi persaingan, perusahaan harus memiliki keunggulan bersaing agar terus dapat bertahan. Salah satu hal yang penting untuk menciptakan keunggulan bersaing ialah dengan fokus kepada konsumen.

Bila dihubungkan dengan konsep experiential marketing (sense, feel, think, act, dan relate). Roxy Mart Kota Palu merangsang pada indera konsumen dengan memberikan sense berupa interior ruangan yang sangat menarik dan nyaman serta kebersihan dan kenyamanan, sebagai feel (perasaan) yang diterima oleh pelanggan. Pelanggan Roxy Mart Kota Palu akan berfikir bahwa pengadaan promo yang diberikan Roxy Mart Kota Palu sangat menarik sehingga membuat pelanggan ingin datang kembali ke Roxy Mart Kota Palu, dengan melakukan penerapan experiential marketing yang baik, maka diharapkan akan berdampak positif terhadap loyalitas pelanggan. Berdasarkan hal tersebut, maka Roxy Mart Kota Palu 
dituntut berusaha menghadirkan pengalaman yang unik, positif dan mengesankan kepada konsumen. Oleh karena itu, konsumen akan merasa terkesan dan pengalaman selama menikmati produk Roxy Mart Kota Palu ini akan tertanam dalam benak mereka. Sehingga nantinya akan tercipta loyalitas pelanggan bagi Roxy Mart Kota Palu.

Adapun tujuan yang ingin dicapai dalam penelitian ini adalah:

1. Apakah komponen-komponen experiential marketing yang terdiri dari sense, feel, think, act, dan relate berpengaruh signifikan secara serempak terhadap loyalitas pelanggan di Roxy Mart Kota Palu?

2. Apakah sense, feel, think, act, dan relate berpengaruh signifikan secara parsial terhadap loyalitas pelanggan di Roxy Mart Kota Palu?

\section{KAJIAN LITERATURE \\ Pengertian Experiential Marketing}

Smilansky $(2009 ; 15)$ menyatakan experiential marketing adalah proses mengidentifikasi dan memuaskan kebutuhan pelanggan dan aspirasi yang menguntungkan, melibatkan pelanggan melalui komunikasi dua arah yang membawa kepribadian merek dalam hidup dan menambah nilai kepada target

pelanggan. Komunikasi dua arah dan keterlibatan interaktif adalah kunci untuk menciptakan pengalaman mengesankan yang mendorong word of mounth, dan mengubah konsumen menjadi pendukung merek dan loyalitas konsumen terhadap suatu merek.

\section{Dimensi Experiential Marketing}

Dimensi experiential marketing Menurut Schmitt, terdapat 5 dasar pembentuk experiential marketing yaitu sense, feel, think, act, dan relate.

a. Sense, Rozaqie, et.al (2016:31) sense adalah untuk menciptakan kesenangan estetika, kegembiraan, keindahan, dan kepuasan melalui rangsangan indera.

b. Feel, Rozaqie, et.al (2016:31) feel adalah pemahaman dari stimulus apa yang dapat memicu emosi tertentu serta kemauan pelanggan untuk terlibat dalam pengambilan perspektif dan empati.

c. Think, Rozaqie, et.al (2016:31) Think menarik untuk melibatkan pelanggan berfikir memusat dan menyebar melalui kejutan (surprise), intrik (intrigue), dan provokasi (provocation).

d. Act, Rozaqie, et.al (2016:31) act adalah untuk memberikan kesan terhadap pola perilaku dan gaya hidup, serta memperkaya pola interaksi sosial melalui strategi yang dilakukan.

e. Relate, Rozaqie, et.al (2016:31) relate adalah menghubungkan konsumen tersebut dengan budaya dan lingkungan sosial yang dicerminkan oleh merek suatu produk.

\section{Loyalitas Pelanggan}

Tjiptono (2014:398) menyatakan loyalitas pelanggan adalah komitmen pelanggan terhadap suatu merek, toko, atau pemasok, berdasarkan sikap yang sangat positif dan tercermin dalam pembelian ulang yang konsisten. Griffin (2005:31) menyatakan bahwa pelanggan yang loyal memiliki karakteristik sebagai berikut:

1. Melakukan pembelian ulang.

2. Membeli antar lini produk dan jasa.

3. Merekomendasikan produk lain.

4. Menunjukkan kekebalan dari daya tarik produk sejenis dari pesaing.

Berdasarkan beberapa pendapat diatas dapat disimpulkan bahwa loyalitas pelanggan adalah perilaku membeli secara berulang-ulang pada produk atau jasa secara teratur dan mereferensikan produk atau jasa tersebut kepada orang lain. Loyalitas pelanggan merupakan salah satu tujuan inti yang diupayakan dalam pemasaran modern. Hal ini dikarenakan dengan loyalitas diharapkan perusahaan akan mendapatkan keuntungan jangka panjang atas hubungan mutualisme yang terjalindalam kurun waktu tertentu. 


\section{Kerangka Pikir}

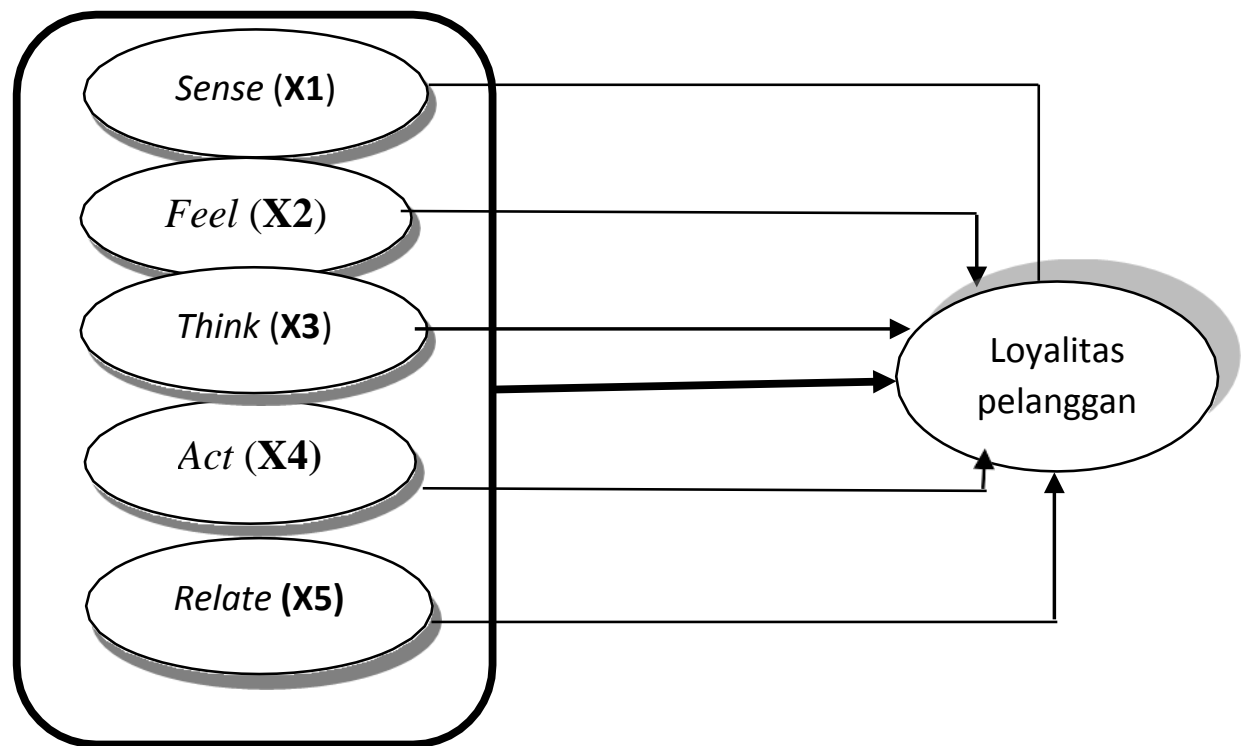

\section{Gambar 1 \\ Kerangka Pikir}

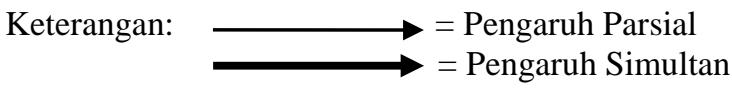

\section{Hipotesis}

Berdasarkan rumusan masalah dan landasan teori yang telah dikemukakan maka dapat disusun hipotesis penelitian sebagai berikut:

1. Komponen-komponen Experiential Marketing (Sense, Feel, Think, Act, dan Relate) berpengaruh signifikan secara simultan terhadap Loyalitas Pelanggan Roxy Mart Kota Palu.

2. Sense berpengaruh signifikan secara parsial terhadap Loyalitas Pelanggan Roxy Mart Kota Palu.

3. Feel berpengaruh signifikan secara parsial terhadap Loyalitas Pelanggan Roxy Mart Kota Palu.

4. Think berpengaruh signifikan secara parsial terhadap Loyalitas Pelanggan Roxy Mart Kota Palu.

5. Act berpengaruh signifikan secara parsial terhadap Loyalitas Pelanggan Roxy Mart Kota Palu.

6. Relate berpengaruh signifikan secara parsial terhadap Loyalitas Pelanggan Roxy Mart Kota Palu.

\section{METODE PENELITIAN}

Penelitian ini dilakukan untuk memperoleh data informasi tentang pengaruh experiential marketing terhadap loyalitas pelanggan (studi pada Roxy Mart Kota Palu). Jenis penelitian ini adalah deskriptif kausal, Sugiyono (2013:42) menyatakan Penelitian kausal merupakan penelitian yang mempunyai tujuan utama yaitu membuktikan hubungan sebab dan akibat atau hubungan mempengaruhi dan dipengaruhi dari variabel yang diteliti. Lokasi dalam penelitian ini adalah Roxy Mart Kota Palu yang bertempat di jalan Suharso, Palu Timur Sulawesi Tengah.

Populasi penelitian ini adalah seluruh pelanggan Roxy Mart Kota Palu. Adapun jumlah pelanggan Roxy Mart Kota Palu tidak diketahui secara pasti. Jumlah sampel yang akan diambil untuk mewakili populasi dalam penelitian ini sebanyak 90 sampel, Jumlah sampel pada penelitian ini merujuk pada teori Roscoe dalam Sugiyono (2016:131) adalah minimal 10 kali dari jumlah variabel yang diteliti (variabel independen + variabel dependen). Jumlah variabel dalam penelitian ini adalah 6 yang terdiri dari variabel independen (Sense, Feel, Think, Act, dan Relate) dan variable dependen (loyalitas pelanggan). Berdasarkan pertimbangan tersebut maka penulis menetapkan jumlah sampel yang digunakan dalam 
penelitian ini 15 x 6 variabel, yaitu 90 responden. Karena populasi tidak diketahui maka peneliti menggunakan teknik penarikan sampel Purposive Sampling.

Adapun metode analisis data dalam penelitian ini, yaitu:

1. Pengujian instrument

a. Uji validitas, Uji validitas adalah sejauh mana kehandalan sebuah alat ukur dalam mengukur apa yang diukur. Instrument yang valid berarti alat ukur yang digunakan untuk mendapatkan data. Jika total skorpositif dan lebih dari $0,3(\mathrm{r} \geq 0,3)$ maka instrument tersebut dinyatakan valid, Sugiyono (2014:188).

b.Uji reabilitas, alat untuk mengukur suatu kuisioner yang merupakan indikator dari variabel dan konstruk. Teknik statistika digunakan Cronbach Alpha. Sebuah faktor dinyatakan reliabel jika koefisien alpha lebih besar dari 0,60 Ghozali (2013:47).

1.Uji asumsi klasik

a. Uji Multikolienaritas, digunakan untuk menguji apakah model regresi ditemukan adanya kolerasi antara variabel bebas independen. Uji multikolinieritas dapat dilakukan dengan cara melihat VIF (Varlance Inflation Faktors) Jika tolerance $\geq 0.10$ atau sama dengan nilai VIF $\leq 10$ maka menunjukan tidak terjadi multikolinieritas, dan sebaliknya (Ghozali, 2013:105-106).

b.Uji Hetersokedastisitas, Ghozali (2013:139) menyatakan uji heteroskedastisitas yaitu untuk menguji apakah dalam model regresi terjadi ketidaksamaan variance dari residual satu pengamatan ke pengamatan yang lain. Dasar pengambilan keputusan, jika tidak ada pola yang jelas, serta titik-titik menyebar diatas dan dibawah angka nol pada sumbu Y, maka tidak terjadi heteroskedastisitas.

c. Uji Normalitas, digunakan untuk menguji apakah dalam sebuah model regresi variabel (pengganggu) dependen dan independen atau keduanya memiliki distribusi normal (Ghozali, 2013:160). Dasar pengambilan keputusan, jika data yang menyebar di sekitar garis diagonal dan mengikuti arah garis diagonal, maka model regresi memenuhi asumsi normalitas.

\section{Regresi Linear Berganda}

Model umum bentuk persamaan alat analisis statistik parametrik Regresi Linear Berganda dapat digambarkan sebagai (Sugiyono, 2014:277).

$$
\mathrm{Y}=\mathrm{a}+\mathrm{b}_{1} \mathrm{X}_{1}+\mathrm{b}_{2}+\mathrm{X}_{2}+\ldots \ldots+\mathrm{bn} \mathrm{Xn}
$$

Bila formasi matematis regresi linier berganda tersebut diaplikasikan dalam penelitian ini, maka akan diperoleh bentuk persamaan sebagai berikut:

Dimana:

$$
Y=a+b_{1} X_{1}+b_{2} X_{2}+b_{3} X_{3}+b_{4} X_{4}+b_{5} X_{5}
$$

$\mathrm{Y}=$ Loyalitas

$\mathrm{X} 1=$ Sense

$\mathrm{X} 2=$ Feel

$\mathrm{X} 3=$ Think

$\mathrm{X} 4=$ Act

$\mathrm{X} 5$ = Relate

$\alpha=$ Konstanta

$\mathrm{b}_{1}-\mathrm{b}_{5}=$ Koefisien Regresi

\section{HASIL DAN PEMBAHASAN}

\section{Hasil Uji Analisis Regresi Linier Berganda}

Penelitian ini menggunakan analisis regresi linear berganda dengan tujuan untuk menguji pengaruh experiential marketing yang terdiri dari sense, feel, think, act, dan relate terhadap loyalitas pelanggan Roxy Mart Kota Palu. lebih jelasnya hasil analisis regresi linear berganda dapat dilihat pada tabel 1 berikut: 
Tabel 1

Hasil Uji Analisis Regresi Linier Berganda

\begin{tabular}{|c|c|c|c|c|c|}
\hline \multicolumn{6}{|c|}{ Variabel Dependen Y = Loyalitas Pelanggan } \\
\hline \multirow{2}{*}{$\begin{array}{c}\text { Variabel } \\
\text { Independen }\end{array}$} & \multicolumn{2}{|c|}{$\begin{array}{c}\text { Unstandardized } \\
\text { Coefficients }\end{array}$} & \multirow{2}{*}{$\begin{array}{c}\begin{array}{c}\text { Standardized } \\
\text { Coefficients }\end{array} \\
\text { Beta }\end{array}$} & \multirow[t]{2}{*}{ t-hitung } & \multirow[t]{2}{*}{ Sig } \\
\hline & B & $\begin{array}{l}\text { Std. } \\
\text { Error }\end{array}$ & & & \\
\hline $\mathrm{C}=$ Constanta & 0,083 & 0,273 & & 0,303 & 0,762 \\
\hline Sense (X1) & 0,248 & 0,082 & 0,265 & 3,012 & 0,003 \\
\hline Feel (X2) & 0,217 & 0,092 & 0,208 & 2,371 & 0,02 \\
\hline Think (X3) & 0,175 & 0,076 & 0,19 & 2,313 & 0,023 \\
\hline Act (X4) & 0,222 & 0,099 & 0,221 & 2,245 & 0,027 \\
\hline Relate (X5) & 0,114 & 0,046 & 0,162 & 2,497 & 0,014 \\
\hline Multiple R & 865 & \multicolumn{2}{|c|}{ sig. $F=0,000$} & \multicolumn{2}{|c|}{$\mathrm{F}=49,831$} \\
\hline \multicolumn{2}{|c|}{ Adjusted R Square $=0,733$} & \multicolumn{2}{|c|}{$\mathrm{R}$ Square $=0,745$} & & \\
\hline
\end{tabular}

Sumber: data diolah

Berdasarkan Tabel 2 di atas, maka dapat ditulis dalam bentuk persamaan regresi linier berganda sebagai berikut:

$$
Y=0,083+0,248 X_{1}+0,217 X_{2}+0,175 X_{3}+0,222 X_{4}+0,114 X_{5}+e
$$

Jika bentuk penjabaran di atas, menunjukan bahwa variabel independen yang dianalisis yaitu variabel $\left(\mathrm{X}_{1}, \mathrm{X}_{2}, \mathrm{X}_{3}, \mathrm{X}_{4}\right.$ dan $\left.\mathrm{X}_{5}\right)$ memberi pengaruh positif terhadap variabel dependen ( $\mathrm{Y}$ ), yaitu loyalitas pelanggan membeli di Roxy Mart Kota Palu. Untuk lebih jelasnya, penjelasan bentuk persamaan tersebut adalah sebagai berikut:

1. Nilai konstanta sebesar 0,083, artinya jika variabel independen (sense, feel, think, act dan relate) bernilai 0, maka variabel dependen (Loyalitas Pelanggan Roxy Mart Kota Palu) nilainnya sebesar 0,083

2. Di lihat dari nilai beta, variabel independen $(\mathrm{X})$ yang berpengaruh paling dominan terhadap variabel dependen (Y) adalah variabel sense (X1) karena variabel tersebut memiliki nilai Beta terbesar yaitu 0,248, sehingga dapat disimpulkan panca indera (sense) pada Roxy Mart Kota Palu adalah faktor yang paling besar pengaruhnya terhadap loyalitas pelanggan.

3. Koefisien regresi sub variabel sense (X1) sebesar 0,248, artinya apabila Roxy Mart Kota Palu melakukan penerapan sense dengan lebih baik lagi, maka loyalitas pelanggan Roxy Mart Kota Palu meningkat sebesar 0,248 .

4. Koefisien regresi sub variabel feel (X2) sebesar 0,217, artinya apabila Roxy Mart Kota Palu melakukan penerapan feel dengan baik lagi, maka loyalitas pelanggan Roxy Mart Kota Palu meningkat sebesar 0,217 .

5. Koefisien regresi sub variabel think (X3) sebesar 0,175, artinya apabila Roxy Mart Kota Palu melakukan penerapan think dengan baik lagi, maka loyalitas pelanggan Roxy Mart Kota Palu meningkat sebesar 0,175 . 
6. Koefisien regresi sub variabel act (X4) sebesar 0,222, artinya apabila Roxy Mart Kota Palu melakukan penerapan act dengan baik lagi, maka loyalitas pelanggan Roxy Mart Kota Palu meningkat sebesar 0,222 .

7. Koefisien regresi (B) sub variabel relate (X5) sebesar 0,114, artinya apabila Roxy Mart Kota Palu melakukan penerapan relate dengan baik lagi, maka loyalitas pelanggan Roxy Mart Kota Palu meningkat sebesar 0,114 .

\section{Hasil Pengujian Hipotesis}

\section{Hasil Pengujian Hipotesis Secara Simultan (Uji F)}

Tahap selanjutnya adalah menguji signifikan hubungan atau uji $\mathrm{F}$ antara variabel experiential marketing yang terdiri dari sense, feel, think, act, dan relate terhadap loyalitas pelanggan. Berdasarkan tabel 2, diperoleh angka signifikan $\mathrm{F}$ sebesar 0,000 . Angka $0,000,<0,05$ hal ini berarti terdapat pengaruh secara simultan pada variabel experiential marketing yang terdiri dari sense, feel, think, act, dan relate terhadap loyalitas pelanggan Roxy Mart Kota Palu dengan besar pengaruh 78,4\%. Oleh karena itu hipotesis diterima.

\section{Hasil Pengujian Hipotesis Secara Parsial (Uji T)}

Pengujian hipotesis secara parsial adalah untuk mengetahui apakah variabel sense, feel, think, act, dan relate secara parsial berpengaruh secara positif dan signifikan terhadap loyalitas pelanggan Roxy Mart Kota Palu. Adapun hasil pengujian secara parsial untuk setiap variabel independen terhadap variabel dependen dapat dilihat dari penjelasan berikut:

1. Hasil Pengujian Hipotesis Kedua

Berdasarkan tabel 2, hasil pengujian SPSS diperoleh hasil angka signifikan t sebesar $(0,003<$ 0,05). maka hipotesis kedua dalam penelitian ini yaitu sense secara parsial berpengaruh signifikan terhadap loyalitas pelanggan Roxy Mart Kota Palu diterima.

2. Hasil Pengujian Hipotesis Ketiga

Berdasarkan tabel 2, hasil pengujian SPSS diperoleh hasil angka signifikan t sebesar $(0,02<$ 0,05). maka hipotesis ketiga (X2) dalam penelitian ini yaitu feel secara parsial berpengaruh signifikan terhadap loyalitas pelanggan Roxy Mart Kota Palu diterima.

3. Hasil Pengujian Hipotesis Keempat

Berdasarkan tabel, hasil pengujian SPSS diperoleh hasil angka signifikan t sebesar $(0,0023<$ 0,05). maka hipotesis ketiga (X3) dalam penelitian ini yaitu think secara parsial berpengaruh signifikan terhadap loyalitas pelanggan Roxy Mart Kota Palu diterima.

4. Hasil Pengujian Hipotesis Kelima

Berdasarkan tabel 2, hasil pengujian SPSS diperoleh hasil angka signifikan t sebesar $(0,027<$ 0,05). maka hipotesis ketiga (X4) dalam penelitian ini yaitu act secara parsial berpengaruh signifikan terhadap loyalitas pelanggan Roxy Mart Kota Palu diterima.

5. Hasil Pengujian Hipotesis Keenam

Berdasarkan tabel 2, hasil pengujian SPSS diperoleh hasil angka signifikan t sebesar $(0,0014<$ 0,05). maka hipotesis ketiga (X5) dalam penelitian ini yaitu relate secara parsial berpengaruh signifikan terhadap loyalitas pelanggan Roxy Mart Kota Palu diterima.

\section{Pembahasan Atau Hasil Analisis \\ Pembahasan Atau Analisis Secara Simultan}

Berdasarkan hasil pengujian serta analisis yang telah dilakukan pada penelitian ini membuktikan bahwa sense, feel, think, act, dan relate secara simultan berpengaruh signifikan terhadap loyalitas pelanggan Roxy Mart Kota Palu. Diketahui dari nilai pengaruh, bisa dijelaskan bahwa pengaruh secara simultan (experiential marketing) terhadap loyalitas pelanggan Roxy Mart Kota Palu adalah sebesar 0,745 $(74,5 \%)$, artinya bauran pemasaran jasa mampu memberikan kontribusi terhadap perubahan keputusan konsumen dengan kemampuan sebesar $74,5 \%$, loyalitas pelanggan yang dipengaruhi oleh variabel selain experiential marketing. 


\section{Pembahasan Atau Analisis Secara Parsial \\ Sense}

Berdasarkan hasil uji parsial, penelitian ini menunjukkan bahwa sense secara parsial berpengaruh signifikan terhadap loyalitas pelanggan Roxy Mart Kota Palu. Artinya hipotesis kedua penelitian ini diterima. Selanjutnya, berdasarkan hasil uji regresi linier berganda menunjukkan bahwa sense berpengaruh positif terhadap loyalitas pelanggan. Artinya, apabila Roxy Mart Kota Palu melakukan penerapan sense dengan lebih baik, maka akan meningkat loyalitas pelanggan Roxy Mart Kota Palu.

\section{Feel}

Berdasarkan hasil uji parsial, penelitian ini menunjukkan bahwa feel secara parsial berpengaruh signifikan terhadap loyalitas pelanggan Roxy Mart Kota Palu. Artinya hipotesis ketiga penelitian ini diterima. Selanjutnya, berdasarkan hasil uji regresi linier berganda menunjukkan bahwa feel berpengaruh positif terhadap loyalitas pelanggan. Artinya, apabila Roxy Mart Kota Palu melakukan penerapan feel dengan lebih baik lagi, maka akan meningkat loyalitas pelanggan Roxy Mart Kota Palu.

\section{Think}

Berdasarkan hasil uji parsial, penelitian ini menunjukkan bahwa think secara parsial berpengaruh signifikan terhadap loyalitas pelanggan Roxy Mart Kota Palu. Artinya hipotesis keempat penelitian ini diterima. Selanjutnya, berdasarkan hasil uji regresi linier berganda menunjukkan bahwa think berpengaruh positif terhadap loyalitas pelanggan. Artinya, apabila Roxy Mart Kota Palu melakukan penerapan think dengan lebih baik lagi, maka akan lebih baik pula loyalitas pelanggan Roxy Mart Kota Palu.

Act

Berdasarkan hasil uji parsial, penelitian ini menunjukkan bahwa act secara parsial berpengaruh signifikan terhadap loyalitas pelanggan Roxy Mart Kota Palu. Artinya hipotesis kelima penelitian ini diterima. Selanjutnya, berdasarkan hasil uji regresi linier berganda menunjukkan bahwa act berpengaruh positif terhadap loyalitas pelanggan. Artinya, apabila Roxy Mart Kota Palu melakukan penerapan act dengan lebih baik lagi, maka akan meningkat loyalitas pelanggan Roxy Mart Kota Palu.

\section{Relate}

Berdasarkan hasil uji parsial, penelitian ini menunjukkan bahwa relate secara parsial berpengaruh signifikan terhadap loyalitas pelanggan Roxy Mart Kota Palu. Artinya hipotesis keenam penelitian ini diterima. Selanjutnya, berdasarkan hasil uji regresi linier berganda menunjukkan bahwa relate berpengaruh positif terhadap loyalitas pelanggan.

\section{PENUTUP}

\section{Kesimpulan}

Berdasarkan hasil analisis dan pembahasan yang dilakukan mengenai pengaruh variabel experiential marketing terhadap loyalitas pelanggan Roxy Mart Kota Palu, maka dapat ditarik kesimpulan:

1. Komponen-komponen experiential marketing yang terdiri dari sense, feel, think, act, dan relate berpengaruh signifikan secara simultan terhadap loyalitas pelanggan Roxy Mart Kota Palu.

2. Sense berpengaruh signifikan secara parsial terhadap loyalitas pelanggan Roxy Mart Kota Palu.

3. Feel berpengaruh signifikan secara parsial terhadap loyalitas pelanggan Roxy Mart Kota Palu.

4. Think berpengaruh signifikan secara parsial terhadap loyalitas pelanggan Roxy Mart Kota Palu.

5. Act berpengaruh signifikan secara parsial terhadap loyalitas pelanggan Roxy Mart Kota Palu.

6. Relate berpengaruh signifikan secara parsial terhadap loyalitas pelanggan Roxy Mart Kota Palu.

\section{Saran}

Berdasarkan kesimpulan yang telah diuraikan sebelumnya, maka saran-saran yang tepat menyangkut kegunaan penelitian ini dapat diuraikan sebagai berikut: 
1. Pihak roxy mart hendaknya selalu menjaga aroma ruangan sehingga dapat membuat pelanggan nyaman saat berada di Roxy Mart Kota Palu.

2. Pihak Roxy Mart Kota Palu hendaknya membuat promo yang ditawarkan dengan konsisten atas promo sebelumnya.

3. Pihak Roxy Mart Kota Palu harus memberikan variasi produk yang beragam agar terlihat menarik.

4. Pihak Roxy Mart Kota Palu hendaknya lebih meningkatkan produk sehingga pelanggan Roxy Mart tidak berpaling ke minimarket lainnya.

\section{REFERENSI}

Griffin, Jill. 2005. Custumer Loyalty: Menumbuhkan Dan Mempertahankan Kesetiaan Pelanggan. Jakarta: Erlangga

Ghozali, Imam 2013. Aplikasi Analisis Multivariate Dengan Program SPSS. Semarang: Badan Penerbit Universitas Diponegoro.

Rozaqie, Nizar., Suharyono., Dan Andriani, Kusmawati, 2016. "Analisis Fakto Faktor Experiential Marketing Dan Pengaruhnya Terhadap Loyalitas Pelanggan (Survei Pada Pelanggan Legend Coffee Malang)”. Jurnal Administrasi bisnis Vol. 38 No. 1. Universitas Brawijaya Malang.

Schmitt, Bernd H. 1999. “Experiental Marketing : How To Get Customers To Sense, Feel, Think, Act, And Relate To Your Company And Brands". New York: The Free Press.

Smilinsky, Shaz, 2009. " Experiential Marketing : A Practical Guide To Interactive Brand Experieces”. USE: London And Philadelphia, Kogan Page.

Sugiyono. 2013. Metode Penelitian Bisnis Kuantitatif, Kualitatif, Dan R\&D. Bandung: Alfabeta.

Sugiyono, 2014. Metode Penelitian Bisnis Kuantitatif, Kualitatif, Dan R\&D. Bandung: Alfabeta.

Sugiyono. 2016. Metode Penelitian Bisnis Kuantitatif, Kualitatif, Dan R\&D. Bandung: Alfabeta.

Tjiptono, Fandy. 2014. Pemasaran Jasa Prinsip, Penerapan, Dan Penelitian. Yogyakarta: Bayumedia Publishing. 